\title{
Os nomes de lugares em rede: um estudo com foco na interdisciplinaridade
}

\begin{abstract}
Karylleila Santos Andrade*
Resumo: O estudo toponímico apenas pode ser compreendido e apreendido a partir dos fios tecidos sob os olhares de diversos saberes. Fruto de um movimento de aglutinação de aspectos sociohistóricos, culturais, geográficos e linguísticos, os nomes de lugares revelam suas origens e dinâmicas; tornando rica a maneira pelo qual os atores sujeitos se utilizam da linguagem para imprimir no espaço uma variedade de significados. A proposta do trabalho é compreender o estudo da toponímia numa perspectiva interdisciplinar, considerando a abordagem da metáfora de rede. Para realizar essa discussão, utilizaremos como subsídios teórico-metodológicos os trabalhos de Dick (1990, 1999 e 2004) no campo da toponímia, os estudos de Fazenda (2001), (2008), (2009) e Morin (1990) no campo da interdisciplinaridade, e a teoria da metáfora de rede terá como base as referências de Alves (2001) e Azevedo (2002).
\end{abstract}

Palavras-chave: toponímia; interdisciplinaridade; metáfora de rede.

Abstract: The toponymic study can only be understood and learned from the wires that have been woven under several looks. From the agglutination movements of sociohistorical, cultural, geographical and linguistic aspects, the names of places reveal their origin and dynamic, making rich the way in which the actors use language to print in space a variety of meanings. The purpose of this work is to understand the toponymy from an interdisciplinary perspective, considering the approach of the network metaphor. To accomplish this discussion, we will use as theoretical-methodological support the works of Dick (1990, 1999 and 2004) in the area of toponymy, the studies of Fazenda (2001), (2008), (2009) and Morin (1990) in the interdisciplinary area, and the theory of network metaphor will be based on references of Alves (2001) and Azevedo (2002).

Keywords: toponymy; interdisciplinarity; network metaphor.

\section{Introdução}

Toponímia vem do grego topos "lugar" e onoma "nome". Estuda o nome dos lugares e designativos geográficos: físico, humano, antrópico ou cultural. Deve ser pensada como um complexo línguo-cultural: um fato do sistema das línguas humanas. Podemos pensar que a relação da toponímia, a partir de uma visão interdisciplinar, estabelece o sentido de unidade diante dos diversos saberes. Ou seja: possibilita ao sujeito re/encontrar a identidade, história, etimologia do nome na multiplicidade de conhecimentos, tendo em vista o plano onomasiológico no ato de dar nomes aos lugares. Para compreender o estudo da toponímia numa perspectiva interdisciplinar,

\footnotetext{
* Doutorado em Linguistica pela Universidade de São Paulo. Professora da UFT.
} 
faremos um percurso teórico-metodológico no campo da metáfora de rede e um estudo de algumas noções no campo da educação: curiosidade epistemológica, conhecimento, aprendizagem significativa, pensamento complexo.

\section{Aprender/ensinar e aprender/tecer: a trama da "Curiosidade epistemológica"}

Ao utilizar-se de uma metáfora, $\mathrm{o}$ ato de tecer, vislumbro e percebo a complexidade das teias de relações que abarcam o conhecimento como categoria essencial do processo educativo. A tecelagem é o ato de tecer, entrelaçar fios de trama ${ }^{2}$, no sentido transversal, e de urdume ${ }^{3}$, no sentido longitudinal, formando tecidos. O urdume são os fios dispostos no comprimento do tecido; a trama é composta dos fios que cruzam, em ângulo reto, os fios do urdume. Os procedimentos que envolvem o ato de tecer são três: abertura da cala, processo que seleciona os fios de urdume formando uma manta de fios mais baixa e uma mais alta; inserção da trama, momento em que o fio é inserido na tecelagem de cala; e, por fim, a batida do pente. A tecelagem pode ser artesanal, processo manual, ou industrial, utilizando teares automáticos. Ver figura abaixo.

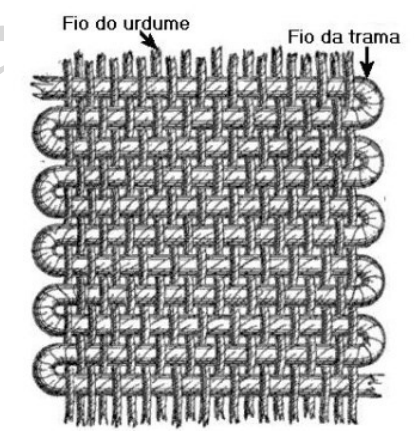

Figura 1- Urdume e trama na tela do tecido ${ }^{4}$.

1 A expressão curiosidade epistemológica é apresentada por Freire (1996) no livro Pedagogia da autonomia: saberes necessários à prática educativa. $\mathrm{O}$ autor escreve: "quanto mais criticamente se exerça a capacidade de aprender tanto mais se constrói e desenvolve o que venho chamando de "curiosidade epistemológica" (grifos nossos), sem a qual não alcançamos o conhecimento cabal do objeto." (Freire 1996: 13)

${ }^{2}$ Conjunto de fios que se cruzam no sentido transversal de um tecido, cruzados pelos da urdidura. Aquilo que foi tecido, teia, tela. (HOUAISS; VILLAR, 2001, p 2747)

${ }^{3}$ Conjunto de fios dispostos longitudinalmente no tear e pelos quais passa o fio da trama. (HOUAISS; VILLAR, 2001, p 2810)

${ }^{4}$ Figura disponível no sítio Disponível no sítio <http://pt.wikipedia.org/wiki/Urdume>. Acesso em: 25 de agosto de 2011. 
O projeto é único: tecer um tecido. Cada elemento no ato de tecer tem suas características, as quais são distintas. Os fios que formam a trama distinguem-se dos fios da urdidura. Para que o tecido seja formado, é preciso que esses fios sejam trabalhados de forma conjunta. A integração é importante, mas não é fundamental. Isto porque no ato de tecer é necessário que haja, além da integração, harmonia entre os fios, cada um em seu sentido, transversal e longitudinal.

No sentido da construção da teia do conhecimento, a integração das diversas ciências não garante a sua perfeita execução. A interdisciplinaridade, nesse caso, aparece como uma possibilidade de enriquecer e ultrapassar a integração dos elementos do conhecimento.

Um dos princípios indispensáveis à formação do professor e à sua prática educativa é que ele se convença de que ensinar não é transferir conhecimento, mas dar possibilidades para sua produção ou a sua construção. Nas palavras de Paulo Freire, não há docência sem discência, ambas se elucidam e seus sujeitos, apesar das diferenças que os conotam, não podem ser reduzidas à condição de objeto um do outro: "Quem ensina aprende ao ensinar e quem aprende ensina ao aprender." (FREIRE, 1996, p. 23).

Quanto mais exercemos a capacidade de crítica $^{5}$ na ação-aprender tanto mais se constrói e desenvolve a curiosidade, sem a qual o conhecimento não é possível de ser alcançado. Isto quer dizer que se o educador espera uma atitude curiosa, reflexiva e provocadora do aluno deve, necessariamente, propor atividades que estabeleçam essa atitude, não a passividade. Para garantir a existência dessa curiosidade e sua permanência, é preciso que esse educador, a priori, ator-sujeito democrático, crítico e também curioso, provoque no ator-sujeito-aprendiz a rigorosidade metódica e a busca pela pesquisa. Inicialmente, esse rigor metódico não tem a ver com a educação de "transferência de saberes" ou tratamento de objetos e conteúdos, mas se estende à produção das condições em que aprender criticamente é plausível. Esse cenário pressupõe a presença de educadores e educandos inventivos, questionadores, provocadores, inquietos, insubmissos, persistentes e humildes diante do conhecimento.

\footnotetext{
${ }^{5}$ Um dos objetivos dos PCN do ensino fundamental é "posicionar-se de maneira crítica, responsável e construtiva nas diferentes situações sociais, utilizando o diálogo como forma de mediar conflitos e de tomar decisões coletivas." (BRASIL, 1996, p. 66)
} 
Podemos pensar que, no exercício investigativo, a ideia é puxar os fios que deram origem aquele conceito, significado, explicação, nó. A amarração deste nó, resultado de fios de trama e de urdidura entrelaçados, pode ser desfeita, refeita, recomposta, matizada. As duas extremidades do nó podem formar outros nós com outras extremidades de outros nós. Os fios, além de nós, podem formar tecidos. Lembremos: na tecelagem, o ato de tecer, entrelaçar fios de trama e urdidura, forma tecidos.

A curiosidade humana e a necessidade de aperfeiçoar fizeram com que o ato de tecer fosse impulsionado do fazer artesanal para o industrial: de construções básicas às mais sofisticadas com desenhos, traçados de fios e cores variadas que se mesclam formando uma infinidade de tipos e texturas. A esse movimento de busca, de entrega às incertezas e dúvidas de não saber, no momento da tessitura dos fios, como será o resultado, chama-se pesquisa. Pesquisar, portanto, é procurar. Mas só procura quem se encontra descontente, quem se sente provocado pelo mundo, quem não se conforma com explicações que the são dadas. $\mathrm{O}$ ato de aprender exige do sujeito-ator criatividade, curiosidade. Não se deve contentar-se com os nós prontos, ou os tecidos acabados. É preciso ir além. Conhecer a matéria-prima é o primeiro passo para entender o processo de fiação, embora isso não seja suficiente para compreender todas as etapas. As indagações continuam: Como os fios são formados? Quais os tipos de fibras? Como são e quais os tipos de texturas? Como o tecido foi produzido, artesanal ou industrial?

É nesse sentido que o conceito de aprendizagem é legitimado pelos PCN (1996, p. 61) como aprendizagem significativa. Ou seja, para que ela possa acontecer, é necessária a disponibilidade para o envolvimento do aluno na aprendizagem, o empenho em estabelecer relações entre os fios já conhecidos e aqueles que lhe são apresentados como novos, em usar os instrumentos (fibras e texturas) adequados que conhece e dispõe para alcançar a maior compreensão possível do tecido que deseja tecer e/ou alinhavar.

Essa aprendizagem exige uma ousadia para se colocar problemas, buscar soluções e experimentar novos caminhos, de maneira totalmente diferente da aprendizagem mecânica, na qual o aluno limita seu esforço apenas em memorizar ou estabelecer relações diretas e superficiais. (BRASIL, 1996, p. 61) 
$\mathrm{Na}$ busca por soluções e experimentações de novos caminhos, respeitar a realidade concreta do aluno permite-lhe criar uma certa intimidade com os conteúdos apreendidos na escola e no seu cotidiano com ser social e ideológico que é. É o aprender com crítica, ética e cidadania. Ensinar, portanto, exige risco, aceitação do novo, rejeição, reinvenção, reavaliação ou, até mesmo, reincorporação de práticas antigas sob novos olhares e vozes. Para tanto, o conhecimento não pode ser visto de forma fragmentada e isolada, os saberes não mais serem abordados apenas de modo disciplinar, mas integrados, inter-relacionados, tramados, entrelaçados em harmonia uns aos outros.

\section{O conhecimento e sua trama: metáfora $^{6}$ da rede}

Quase sempre há possibilidade de olhar ou de olhares sobre o outro, ou até mesmo, sobre outros sentidos para conceber ou apreender o cotidiano. Os fios de texturas e espessuras diferentes vão se entrelaçando ou puxando fios de outros tecidos. $\mathrm{Na}$ academia, essa exigência de entrelaçar, tramar fios de tecidos já conhecidos a outros fios desconhecidos se faz cada vez mais urgente. Aos similares, dá-se os nós, tecendo uma outra trama. Aos opostos, abandona-se, desfazendo, desfiando ideias já antes tramadas. Algumas teias já tecidas são desprendidas, destecidas e alguns fios, ainda que seja um só, são prendidos a outros, formando novos nós, nova trama.

Em um cenário de certezas e incertezas, de fios conhecidos e desconhecidos que são tramados a outros fios já antes experimentados e outros ignorados, Azevedo (2002, p. 59) chama a atenção para contextualizar os autores (tecidos) já conhecidos, identificar suas matrizes teóricas (matéria prima fibrosa), identificar pontos de aproximação e de distanciamento entre eles, tramando fios, texturas e cores diversas, tecidos que se entrelaçam a outros formando novos tecidos, ou reinventando os antigos.

\footnotetext{
${ }^{6}$ (...) o locus da metáfora não é de forma alguma na linguagem, mas sim na forma através da qual conceptualizamos um domínio mental em termos de outro. A Teoria Geral da Metáfora é dada pela caracterização de tais mapeamentos entre domínios. E nesse processo, conceitos abstratos rotineiros, como tempo, estado, mudança, causatividade e propósito, também, mostram-se como processos metafóricos. (LAKOFF, 1992, p. 1)
} 
A rede como metáfora nos possibilita reinventar, historicizar atos e pensamentos se partimos que nada surge do nada, que tudo está de alguma forma ligado a tudo. Por historicizar Azevedo entende puxar os fios, "desenovelar, desdobrar as redes ou, ao contrário, enredar fios, a metáfora escolhida ajuda, como tantas outras usadas, a organizar os pensamentos” (2002, p. 60). O conceito de metáfora aqui utilizado não está relacionado apenas ao campo da linguagem, mas está presente em todos os lugares do cotidiano, ou melhor, no pensamento e nas ações. Os modos de ver, pensar e agir do homem são, necessariamente, metafóricos. Esse conceito é visto como fenômeno cognitivo, apartado de sua função puramente retórica na linguagem. De acordo com Lakoff $(1992$, p. 1), a teoria clássica sobre metáforas é inadequada, uma vez que algo que era visto como meramente governando o uso lexical na linguagem, na realidade manifesta princípios governados pelo pensamento. $\mathrm{O}$ autor acrescenta que processos metafóricos extrapolam o nível das expressões novas e de efeito, e na realidade se aplicam ao discurso, na linguagem ordinária do dia-a-dia.

$\mathrm{Na}$ direção do desenovelar/enrolar fios, o pensamento moderno continua a se apropriar da ideia de estabilidade. A hegemonia desse pensamento implica segurança, mas diante da impossibilidade que a pluralidade e a complexidade do real permitem ser elucidados por ele, desprende-se, gerando uma crise. A partir daí abrem-se oportunidades para o surgimento de novos paradigmas.

Em meio à crise e à possibilidade de surgimento de novos paradigmas, Alves assegura que são dois os modos que, hoje, se defrontam/complementam na percepção do conhecimento e a subjetividade.

(...) o primeiro é o dominante na sociedade chamada moderna, sendo representado pela metáfora da árvore; o segundo, sempre existindo nos espaçostempos ${ }^{7}$ da vida cotidiana, passa a ser assumido pelos setores econômicos, científicos e sociais mais dinâmicos, a partir da década de 50 do século XX, e que é representado pela metáfora da rede. "Tecer conhecimento em rede" é a forma possível para indicar como, sempre, o conhecimento foi criado nos vários e diferentes

\footnotetext{
${ }^{7}$ De maneira crescente, tenho buscado discutir com o modo moderno de pensar, mostrando que é necessário um modo de escrever que busque outra maneira, diferente da dicotomizada, de falar da vida. Um desses modos é unir termos que sempre foram ditos separados e mesmo em oposição, indicando que só têm sentido ditos em uma só palavra. (ALVES. Redes cotidianas de conhecimentos e valores nas relações com a tecnologia. s/d. p.1. Disponível no sítio <http://www.labeduimagem.pro.br/frames/seminarios/pdf/apresI.pdf.>)
} 
contextos cotidianos do viver humano, mesmo quando para se fazerem, a ciência e o poder econômico precisaram dizer que os conhecimentos práticos só existiriam enquanto não fossem superados pelo conhecimento verdadeiro, aquele produzido pela ciência, pela burocracia e em outros lugares de poder. (ALVES, N. Ética, estética e subjetividade. $\mathrm{s} / \mathrm{d}$. p. 1 . Disponível no sítio http://www.rizoma.ufsc.br/pdfs/922-of9-st2.pdf) (Grifos da autora)

Considerando a afirmação da autora, percebemos que os conhecimentos práticos/de uso receberam a designação genérica de senso comum, não se reconhecendo neles a sua variedade, multiplicidade e complexidade, nem mesmo a possibilidade e necessidade de mudanças. É certo, nos dias de hoje, que essa designação é por demais precárias para descrever, discutir e analisar as práticas cotidianas e seus processos de reprodução e criação.

No caso específico da escola, compreendidos os modos de conceber o conhecimento, a metáfora da árvore é o dominante. A ideia que marca a escola no cenário da metáfora da árvore é o modo de construção do conhecimento: seleção de conteúdos (o que "deve" e o que "não deve" ser ensinado), estabelecendo uma hierarquização, disciplinarização (conteúdos são estipulados em disciplinas, resultando em currículos oficiais). O pensamento marca a linearidade, a realidade curricular é construída e amparada por disciplinas teóricas, compreendidas como formadoras de um campo científico específico. Os conteúdos dessas disciplinas são considerados na metáfora da árvore como os necessários e aceitáveis para serem escolarizados.

Caminhando na contramão da metáfora da árvore, cientistas e sujeitos de vários campos do saber, a partir de meados do século XX, iniciam uma discussão no modo de conceber o conhecimento, já que as próprias mudanças, transformações ou revoluções na vida exigiam esse pensar/fazer ${ }^{8}$. Surge, então, uma nova metáfora de como se produz o conhecimento: a rede.

A rede implica e permite uma racionalidade aguçada, mais 'complexa'. A noção de complexidade, ou melhor de complexificação, [tem a ver com] a ideia segundo o qual o

${ }^{8}$ (Grifo nosso) Utilizamos aqui a mesma referência de Nilda Alves no texto Redes cotidianas de conhecimentos e valores nas relações com a tecnologia "unir termos que sempre foram ditos separados e mesmo em oposição, indicando que só têm sentido ditos em uma só palavra". (Disponível no sítio $<\underline{\text { http://www.lab-eduimagem.pro.br/frames/seminarios/pdf/apresI.pdf.) }}$ 
pensamento vai do complexo (analisado por redução) ao mais complexo (captador re-produção), tal como a própria prática social. (...) (LEFEBVRE, 1983, p. 35-36 apud ALVES. Redes cotidianas de conhecimentos e valores nas relações com a tecnologia. s/d. p. 7. Disponível no sítio $<\mathrm{http} / / \mathrm{www} . l \mathrm{lab}-$ eduimagem.pro.br/frames/seminarios/pdf/apresI.pdf.>).

O diferencial na introdução da noção de rede é o critério de seleção pautado na prática social. É o momento do reencontro com o senso comum, o empírico, o cotidiano, o que possibilita um espaço de crítica e busca pela revisão da linearidade hegemônica implantada pela metáfora da árvore. A metáfora da rede procura valorizar o grupo, a interação, os contextos, a complexidade, a mudança.

$\mathrm{Na}$ visão da estudiosa Alves, a árvore e a rede são metáforas do pensamento, do conhecimento e dos saberes que podem ser concebidos a partir de diferentes paradigmas, representados imageticamente. A árvore representa a seleção, a hierarquização, a disciplinarização, a normalização e a grupalização do conhecimento. É a educação concentrada na dicotomia do certo e do errado, do promovido e repetido, do diplomado e do marginalizado. Enquanto a rede representa um número ilimitado de caminhos, a racionalidade aguçada e complexa, a superação da linearidade. $\mathrm{Na}$ acepção da autora, é a pedagogia da práticateoriaprática, de conhecimentos tramados e tecidos nos múltiplos espaçotempos e contextos.

Morin (1990) adianta que a palavra complexidade não possui uma nobre herança filosófica, científica ou epistemológica. Ao contrário, padece de uma carga semântica negativa, porque transporta no seu íntimo conflito, insegurança, dúvida e desordem. $\mathrm{O}$ dicionário Houaiss (2001, p. 776) registra o verbete como "qualidade do que é complexo.".Já o verbete complexo é registrado como

\footnotetext{
"1. Diz-se de ou conjunto, tomado como um todo mais ou menos coerente, cujos componentes funcionam entre si em numerosas relações de interdependência ou subordinação, de apreensão muitas vezes difícil pelo intelecto e que geralmente apresentam diversos aspectos. Etm. Lat. complexus, a, um part. pas. de complecti 'cercar, abarcar, compreender. (HOUAISS; VILLAR 2001, p. 776 e 777)
}

A definição inicial de complexidade não pode servir de base ou referência para o conceito na perspectiva de Morin. Para ele, é uma palavra problema e não uma palavra 
solução. Não pode ser definida de maneira simples, nem tão pouco tomar o lugar da simplicidade.

Morin discute a coexistência, nos dias de hoje, de diversas formas de pensar. Apresenta o paradigma da complexidade como aquele capaz de aceitar uma proximidade maior com o real em sua multidimensionalidade. A complexidade no ato de pensar sugere pensar nos contrários como sendo alternativos e complementares; implica a dialética e o dialógico.

É pensar o todo nas partes e as partes no todo, numa perspectiva holográfica, como um caleidoscópio. O todo e as partes estão ali, mas a cada vez que se olha eles se apresentam com um certo desenho, sempre inovando. O todo é mais do que a soma das partes, porque possui mais propriedades e qualidades do que cada parte separado. Mas, ao mesmo tempo, é também menos, ao se constituir, impõe limites às partes, que perdem a liberdade. (AZEVEDO, 2002, p. 64)

A noção de rede está conectada, correlacionada ao paradigma ${ }^{9}$ da complexidade; é, pois, uma das inúmeras possibilidades de se lidar com a questão da complexidade. É a fatia de um movimento que vem se consolidando na "contramão" de um paradigma simplificador $^{10}$, que é o paradigma hegemônico. Essa concepção determinista e mecanicista de ver o mundo é predominantemente no pensamento científico clássico. Este princípio de organização do pensamento apartou campos do conhecimento como a matemática, a química e as chamadas ciências humanas, o que resultou na especialização disciplinar. Daí o efeito saber parcelado, saber disposto em disciplinas. O conhecimento científico moderno foi construído a partir da noção de separabilidade, estabelecido por Descartes, referindo-se ao princípio cartesiano de que era preciso reduzir o complexo ao simples ao observar, examinar e pesquisar determinado fenômeno. Na perspectiva de Morin, a desordem, a totalidade e a multiplicidade são elementos inconcebíveis no pensamento simplificador.

\footnotetext{
${ }^{9}$ A palavra paradigma é empregada frequentemente. Na nossa concepção, um paradigma é constituído por um certo tipo de relação lógica extremamente forte entre noções mestras, noções chave e princípios chave. Esta relação e estes princípios vão comandar todos os propósitos que obedecem inconscientemente ao seu império. (MORIN, 1990, p. 85)

10 [...] o paradigma da simplicidade é um paradigma que põe ordem no universo e expulsa dele a desordem. A ordem reduz-se a uma lei, a um princípio. A simplicidade vê, quer o uno, quer o múltiplo, mas não pode ver que o Uno pode ser ao mesmo tempo Múltiplo. O princípio da simplicidade quer separar o que está ligado (disjunção), quer unificar o que está disperso (redução). (MORIN, 1990, p. 86).
} 
É neste sentido que o estudo dos nomes de lugares sugere um movimento de aglutinação de múltiplos aspectos sociohistóricos, culturais, geográficos e linguísticos. Não deve ser visto como um estudo de saberes partilhados, despedaçados e isolados, apenas sob o enfoque disciplinar. Pensar o estudo toponímico é pensar "o todo nas partes e as partes no todo, numa perspectiva holográfica" como apresenta Azevedo (2002, p. 64).

O que se pretende com este trabalho é compreender o espaço do estudo toponímico na perspectiva da metáfora de rede, procurando valorizar além do conhecimento científico de diversas áreas numa perspectiva interdisciplinar, multidimensional e complexa, a interação e integração de saberes do senso comum do grupo que nomeia os lugares Uma das especificidades na introdução da noção de rede, neste estudo em particular, é o critério de seleção pautado na prática social, como exemplificação o estudo da memória e história oral a fim de compreender a escolha do nome de um acidente humano. Pois, os nomes de lugares revelam a origem e a dinâmica dos lugares; tornando rica a maneira pelo qual os atores sujeitos se utilizam da linguagem para imprimir no espaço uma variedade de significados.

Ao reconhecer que o conhecimento como rede imprime a ideia de valorizar as relações que se constituem entre os diversos objetos e acontecimentos, podemos deduzir que os significados se estabelecem na verdade em feixes de relações. Nesse sentido, será que não podemos pensar, igualmente de forma metafórica, o conteúdo de toponímia em rede? Rede que é trançada a partir de fios diversos, com uma trama que se constitui a partir da proximidade dos traços de seus fios. Ainda que, a princípio, fios com texturas e espessuras diferentes possam causar estranhamento e não proximidade na hora da trama. Ou melhor: desordem e discordância, a priori, podem sim provocar distanciamento na tessitura se considerarmos a ótica de um pensamento linear. Por outro lado, o tumulto e a confusão podem também resultar em um esforço de compreensão das partes no todo, já que o todo apresenta-se com mais características e predicados do que cada parte em separado. É, pois, na desordem aparente e na multiplicidade de aspectos socioculturais, psicológicos, antropológicos, geo-históricos e linguísticos que visualizamos o estudo toponímico. 


\section{Toponímia: uma trama tecida fio a fio}

Antes de darmos continuidade à discussão do estudo toponímico numa perspectiva interdisciplinar, considerando a abordagem da metáfora de rede, faz-se necessário apresentar e discutir o termo interdisciplinaridade. O termo é composto por um prefixo 'inter-' e um sufixo '-dade', os quais são justapostos ao substantivo disciplina. Depreende-se dessa junção uma possibilidade interpretativa, onde: 'inter'-, prefixo de origem latina, significa posição ou ação intermediaria, reciprocidade, interação. Por sua vez, - 'dade', sufixo latino, tem a característica de substantivar alguns adjetivos, conferindo o sentido de ação ou resultado de ação, qualidade, estado ou, ainda, modo de ser. O substantivo 'disciplina', parte chave do termo, significa 'epistemé', podendo ser caracterizado como ordem que assenta ao funcionamento duma organização. "A interdisciplinaridade nomeia um encontro que pode ocorrer entre os elementos 'inter', num certo fazer, e 'dade' a partir da direcionalidade da consciência, pretendendo compreender o objeto, com ele relacionar-se, comunicar-se." (ASSUMPÇÃO, 2009, p. 24)

Partindo para uma discussão sobre o conceito de interdisciplinaridade, Fazenda (2001) afirma que ela surgiu na Europa, em meados da década de sessenta, tendo sido bem mais intenso na França e Itália, época em que nasceram os movimentos estudantis, reivindicando um novo estatuto de universidade e de escola. Aparece, inicialmente, como tentativa de elucidação e de classificação temática das propostas educacionais que começavam a aparecer na época, evidenciando-se através do compromisso de alguns professores em certas universidades, os quais buscavam o rompimento a uma educação por migalhas. A autora coloca que a interdisciplinaridade nasceu como oposição a todo conhecimento que privilegiava o capitalismo epistemológico de certas ciências, como oposição à alienação da Academia às questões da cotidianidade, às organizações curriculares que evidenciavam a excessiva especialização e a toda e qualquer proposta de conhecimento que limitava o olhar do aluno numa única, restrita e limitada direção à patologia do saber. Desde 1970 que a palavra interdisciplinaridade tenta construir um caminho que seja trilhado por um saber coletivo e sintonizado com outras disciplinas. Nessa época, buscava-se uma estruturação conceitual básica. A preocupação era de conceituar, definir a interdisciplinaridade, buscando uma explicitação terminológica. 
"Em 1970 a organização teórica do movimento da interdisciplinaridade procurava uma definição de interdisciplinaridade; em 1980 tentava explicitar um método para a interdisciplinaridade; e em 1990 partiam para a construção de uma teoria da interdisciplinaridade". (FAZENDA, 2001, p. 18)

Falar de interdisciplinaridade é falar de insegurança. Professores que se envolvem com a causa interdisciplinar vivenciam a perplexidade diante de sua implementação na educação: tentativa de construção de novos projetos para o ensino. A questão da insegurança está relacionada ao paradigma emergente ${ }^{11}$ do conhecimento. Estamos chegando ao fim de um período de hegemonia de uma certa ordem científica. Assim como no caso da ciência moderna em que Descartes exerceu a dúvida no lugar de sofrer, é necessário que "a ciência pós-moderna assuma a insegurança em vez de a postergar, mas assumir a insegurança pressupõe o fato de a exercer com responsabilidade." (FAZENDA, 2009, p. 16)

Considerando a insegurança como um elemento que perpassa o pensar interdisciplinar, deparamo-nos ainda com os múltiplos conceitos que variam de autor para autor, bem como a diferenciação de aspectos tais como: multi, pluri, inter e transdisciplinaridade. Embora saibamos que existam variações conceituais entre autores, percebemos que todos se baseiam na ideia de inter-ação entre as disciplinas ou áreas do conhecimento. As diferenças ou nuances que sofrem os diversos conceitos são percebidas no grau de interação da ação interdisciplinar. Japiassú (1976) apresenta classificações dos contínuos graus de relação entre as disciplinas que governam a interdisciplinaridade na pesquisa. A mais aceita é a classificação proposta por Eric Jantsch (1972) apud Japiassú (1976, p. 73-74), a qual compreende 4 níveis, a saber: multidisciplinaridade, pluridisciplinaridade, interdisciplinaridade e transdisciplinaridade.

- Multidisciplinaridade - "se caracteriza por uma ação simultânea de uma gama de disciplinas em torno de uma temática comum.” (JAPIASSU, 1976 apud

11 O conhecimento do paradigma emergente tende assim a ser um conhecimento não dualista, um conhecimento que se funda na superação das distinções tão familiares e óbvias que até há pouco considerávamos insubstituíveis, tais como natureza/cultura, natural/artificial, vivo/inanimado, mente/matéria, observador/observado, subjetivo/objetivo, coletivo/individual, animal/pessoa. (SANTOS, 1988, p. 14) 
CARLOS, 2007, p. 164). Essa ação ainda é muito fragmentada, no sentido em que não se empreende na relação entre os conhecimentos disciplinares e não há nenhum tipo de cooperação entre as disciplinas. Isto quer dizer que representa um estágio inicial de integração que antecede a interdisciplinaridade. Observe a figura 2 (adaptado de SANTOS, 2007, p. 164)

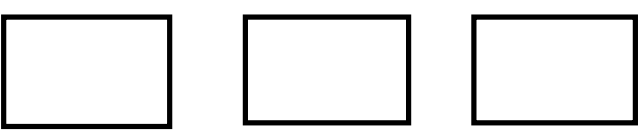

Figura 2 - Multidisciplinaridade

Neste nível de interação os conhecimentos estão estagnados, não existe o princípio entre eles.

- Pluridisciplinaridade - justaposição de diversas disciplinas situadas geralmente no mesmo nível hierárquico e agrupadas de modo a fazer aparecer as relações existentes entre elas. [...] Tipo de sistema: sistema de um só nível e de objetivos múltiplos; cooperação, mas sem coordenação (JAPIASSÚ, 1976, p. 73). Observe a figura 3, adaptada de Santos (2007, p. 164)

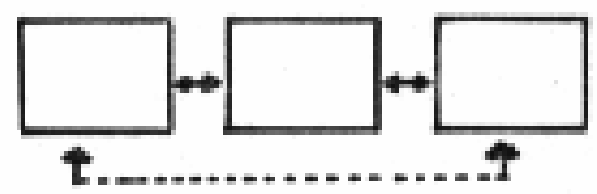

Figura 3 - Pluridisciplinaridade

Embora os conhecimentos estejam situados ainda em um mesmo nível hierárquico, a interação já se faz presente, iniciando um diálogo entre os saberes.

- Interdisciplinaridade - Conforme Japiassú (1976), este momento se caracteriza pela presença de uma axiomática comum a um grupo de disciplinas conexas e definida no nível hierárquico imediatamente superior, o que introduz a noção de finalidade. Observe a figura 4, adaptada de Santos (2007, p. 164) 


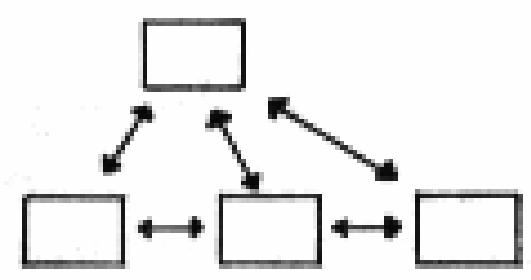

Figura 4 - Interdisciplinaridade

Este estágio representa um nível mais evidente de interações, diálogos entre os conhecimentos ou disciplinas. Segundo os PCN,

A interdisciplinaridade supõe um eixo integrador, que pode ser o objeto de conhecimento, um projeto de investigação, um plano de intervenção. Nesse sentido, ela deve partir da necessidade sentida pelas escolas, professores e alunos de explicar, compreender, intervir, mudar, prever, algo que desafia uma disciplina isolada e atrai a atenção de mais de um olhar, talvez vários (BRASIL, 2002, p. 88-89).

- Transdisciplinaridade - este quarto estágio se encontra em um nível avançado da interdisciplinaridade. Japiassú (1976) a define como sendo uma espécie de coordenação de todas as disciplinas e interdisciplinas do sistema de ensino inovado, sobre a base de uma axiomática geral. Observe a figura 5, adaptada de Santos (2007: 165)

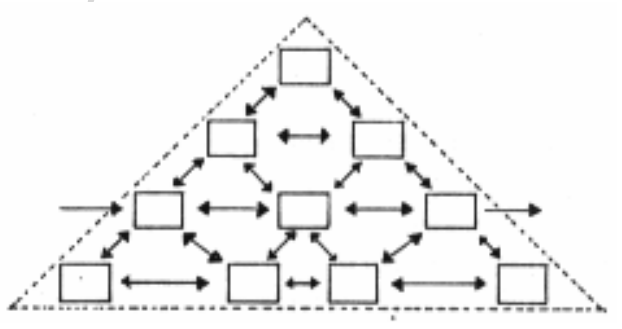

Figura 5 - Transdisciplinaridade

O que se percebe, neste nível de interação, é uma engrenagem de diversos sistemas interdisciplinares num contexto maior de atuação.

Considerando os níveis de estágios pelo qual passa a interdisciplinaridade, deternos-emos, a partir de então, a uma discussão mais focada na toponímia: o diálogo que é tramado entre os saberes que tecem o estudo da toponímia. É importante observar que para qualquer perspectiva ou empreendimento interdisciplinar é preciso, a priori, uma reflexão epistemológica cautelosa do projeto que tem como objetivo a cooperação entre 
várias disciplinas, o que, necessariamente, provoca intercâmbios reais. No entanto, isto exige por parte dos atores envolvidos reciprocidade no ato da permuta de saberes e, consequentemente, enriquecimentos mútuos. Refletir o ato interdisciplinar enquanto ciência possibilita avanços no ensino, sendo que tais progressos podem permitir a realização de novos projetos concretos de pesquisa que, em parte, possam corresponder ao novo paradigma emergente que está surgindo, já discutido anteriormente. Mas não nos animemos muito, esse paradigma está apenas iniciando. É preciso lembrar que a insegurança, perplexidade diante do complexo, ainda é um aspecto relevante a se trabalhar nesse novo paradigma.

Pensando em termos de ensino, os currículos, em sua grande maioria, estão organizados pelas disciplinas tradicionais, o que conduz o aluno apenas a um amontoamento de informações que, quase sempre, não tem validade para o seu aprendizado pessoal ou profissional. Lembremos que o desenvolvimento na era da tecnologia é diverso e muito rápido. Às vezes nem aprendemos a lidar corretamente com uma ferramenta tecnológica, e ela já está ultrapassada. A troca de informação entre os sujeitos-atores, que frequentam a escola, acontece numa velocidade que o ambiente do ensino não tem como acompanhar, sistematizar, enquanto saber, estratégias ou metodologias de ensino nas diversas áreas do conhecimento. É como se ela estivesse sempre atrás do que já não é mais novo, é velho. O que a escola faz diante desse cenário? Um das possibilidades é inserir mais disciplinas ao currículo já tradicional e inoperante, o que só amplia o número de informações e atomiza o conhecimento.

A proposição de um pensar interdisciplinar parte do princípio de que nenhuma forma de conhecimento é em si racional. A ideia que permeia esse pensar é o diálogo com outras formas de conhecimento, incluindo aqui o senso comum como válido. $\mathrm{O}$ saber/fazer interdisciplinar pressupõe apropriar-se do conhecimento científico e tecnológico no uso, seja em relação a questões sociais, individuais ou políticas. O uso dessa prática tende a uma dimensão utópica e libertadora. "Nossa "formação/educação" cotidiana, portanto, se faz em processos complexos (MORIN, 1990, p. 1996) e em contatos múltiplos e diversos com saberes transversais (GUATTARI, 1995; DELEUZE; GUATTARI 1995 apud ALVES. Disponível no sítio: $<$ http://www.rizoma.ufsc.br/pdfs/922-of9-st2.pdf $>$ ). 
Considerando a interdisciplinaridade numa perspectiva da metáfora de rede, em que os fios vão se entrelaçando a outros fios conhecidos e/ou desconhecidos, o estudo toponímico não poder ser pensado desvinculado de outras ciências: “é uma disciplina que se volta para a História, a Geografia, a Linguística, a Antropologia, a Psicologia Social e, até mesmo, à Zoologia, à Botânica, à Arqueologia, de acordo com a formação intelectual do pesquisador" (DICK, 1992, p. II). Deve ser pensada como um complexo línguo-cultural: um fato do sistema das línguas humanas. Faz parte de uma ciência maior que se subdivide em toponímia, estudo do nome de lugar, e antroponímia, estudo do nome de pessoas. Como explicita Ullmann (1964, p. 161), “o estudo dos nomes próprios ou onomástica pode esclarecer muitos aspectos da história política, econômica e social". Ver quadro a seguir:

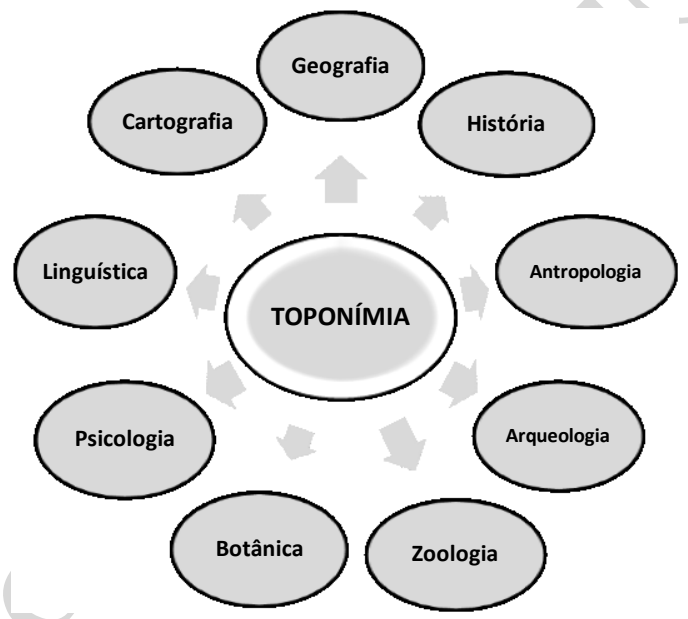

Figura 6 - Estudo Toponímico em rede

Pensando na proposta de estudo toponímico em rede, o qual deve ser mediatizado a partir de relações dinâmicas e de cooperação entre as disciplinas do conhecimento, Morin (1990) nos chama atenção para a necessidade de tomar consciência da complexidade de toda a realidade - física, biológica, humana, social, política. De um lado, o autor observa que as ciências humanas não percebem os caracteres físicos e biológicos dos fenômenos humanos e, de outro, que as ciências naturais não percebem sua inscrição numa cultura, numa sociedade, numa história. Essa distância existente entre as ciências assinala a necessidade da interdisciplinaridade e, como observa o autor, esse problema não se resolve dentro de uma concepção simplista de adição ou acoplagem de conhecimentos. 
Fragmentar o conhecimento é descaracterizá-lo em sua essência etimológica "Conhecer: procurar saber, aprender a conhecer, tomar conhecimento de, reconhecer" ${ }^{\prime 2}$. Mas descaracterizá-lo numa sociedade da informação na qual vivemos hoje é algo que compromete o próprio homem nas respostas e porquês.

Por outro lado, podemos pensar que a relação da toponímia, a partir de uma visão interdisciplinar, estabelece o sentido de unidade diante dos diversos saberes. Ou seja: esse modo de pensar pode possibilitar ao sujeito re/encontrar a identidade, história, etimologia do nome na multiplicidade de conhecimentos, tendo em vista o plano onomasiológico no ato de dar nomes aos lugares. Quando delimitamos, dentro da realidade, um recorte que necessita ter um nome atribuído, não podemos conferir a ele uma fragmentação. Pelo contrário, as suas múltiplas possibilidades e mediações históricas que o estruturam e determinam fazem parte da totalidade, algo dissociável de ser destituído.

É entre a fronteira do pensamento linear e não linear que o estudo da toponímia pode traduzir o modus vivendi de um grupo, um país, ou ainda responder a vários interesses. Na geografia, a toponímia pode dar informações relevantes sobre vários aspectos: relevo, flora, fauna, etc. Pode ainda auxiliar na delimitação da separação entre duas zonas geográficas (por exemplo, entre a zona dos cocais e a caatinga do sertão brasileiro). É considerada uma fonte de informação para os historiadores (colonização, imigração, história oral, etc.), antropólogos (identidade, relação homem, cultura e meio social), biólogos (nomes de seres que compõem determinado bioma), botânicos (nomes de plantas) e outros pesquisadores. A linguística, particularmente, permite estudar a evolução fonética, a etimologia, os aspectos morfossintáticos e semântico-lexicais.

É fundamental compreender os topônimos a partir dos diferentes significados, olhares e áreas de atuação, pois, por se organizarem de maneira dinâmica, constantemente (re) inventam-se no tempo e no espaço, sobrepondo-se valores socioculturais, econômicos, políticos e religiosos. O estudo toponímico apenas pode ser compreendido e apreendido a partir dos fios tecidos sob os olhares de diversos saberes.

${ }^{12}$ HOUAISS, A.; VILLAR, M. S. Dicionário Houaiss de língua portuguesa. Rio de Janeiro: Objetiva, 2001 


\section{Considerações finais}

Retomando o ato de tecer, enxergamos na toponímia a complexidade das teias de relações que envolve o ato de nomear lugares. Os fios de trama e os de urdume se cruzam nas diversas ciências: antropologia, geografia, história, psicologia, linguística e outras, mas também se cruzam com o senso comum: a memória, o cotidiano, apropriando-se do pensamento não-linear.

Fruto de um movimento de aglutinação de aspectos sociohistóricos, culturais, geográficos e linguísticos, os nomes de lugares revelam a origem e a dinâmica dos lugares, tornando rica a maneira pela qual os atores sujeitos se utilizam da linguagem para imprimir no espaço uma variedade de significados. $\mathrm{O}$ ato de nomear expõe como as pessoas se relacionam com os seus lugares, pensam, vivem e experimentam o espaço em sua plenitude.

A princípio, este estudo intenciona provocar uma discussão no sentido de repensar o estudo dos nomes de lugares a partir de uma abordagem mais interativa e dinâmica voltada ao contexto do ensino. Para isto, na perspectiva do estudo em rede, os topônimos podem ser compreendidos como arquivos, que guardam e resguardam a cosmovisão de um grupo, memória e a origem do lugar. Neste sentido, devem ser entendidos como elementos com potencial para valorizar a identidade de uma comunidade ou de um espaço, no caso mais específico deste estudo, o contexto escolar.

\section{Referências Bibliográficas}

ALVES, N.. Redes cotidianas de conhecimentos e valores nas relações com a tecnologia. Disponível no sítio $<$ http://www.labeduimagem.pro.br/frames/seminarios/pdf/apresI.pdf.> Acesso em: 7 de março de 2011.

.Cultura e cotidiano escolar. Disponível no sítio $\overline{<\mathrm{http}: / / w w w . s c i e l o . b r / p d f / r b e d u / n 23 / n 23 a 04 . p d f}$. $>$ Acesso em: 5 de março de 2011.

Ética, estética e subjetividade. Disponível no sítio http://www.rizoma.ufsc.br/pdfs/922-of9-st2.pdf). Acesso em: 8 de março de 2011. 
ASSUMPÇÃO, I. Interdisciplinaridade: uma tentativa de compreensão do fenômeno. In: FAZENDA, I. C. A. (Org.); FELDMAN, M. (Org.); PASSOS, L. F. (Org.). Práticas Interdisciplinares na Escola. 11. ed. São Paulo: Cortez, 2009. 147 p

AZEVEDO, J. G. A tessitura do conhecimento em redes. In: OLIVEIRA, I. B.; ALVES, N.(orgs). Pesquisa no/do cotidiano das escolas: sobre redes de saberes. 2. ed. Rio de Janeiro: DP\&A, 2002. 157p.

BRASIL. Secretaria de Educação Fundamental. Parâmetros curriculares nacionais: introdução aos parâmetros curriculares nacionais / Secretaria de Educação Fundamental. - Brasília: MEC/SEF, 1997. 126p. Disponível no sítio http://portal.mec.gov.br/seb/arquivos/pdf/14_24.pdf. Acesso em: 3 de janeiro de 2011.

PCN + Ensino Médio: Orientações educacionais complementares aos Parâmetros Curriculares Nacionais. Ciências humanas e suas tecnologias. Brasília: Ministério da Educação, 2002.

Secretaria de Educação Básica. Linguagens, códigos e suas tecnologias/Secretaria de Educação Básica. - Brasília: Ministério da Educação, Secretaria de Educação Básica, 2006. 239 p. (Orientações curriculares para o ensino médio; volume 1). Disponível no sítio http://portal.mec.gov.br/seb/arquivos/pdf/book_volume_01_internet.pdf. Acesso em:: 4 de janeiro de 2011.

CARLOS, J. G.. Interdisciplinaridade no Ensino Médio: desafios e potencialidades. 2007. 172 f. Dissertação (Mestrado Profissionalizante em Ensino de Ciências) Programa de Pós-graduação em Ensino de Ciências, Universidade de Brasília, Brasília, 2007.

DICK, M. V. P. A. A motivação toponímica e a realidade brasileira. São Paulo: Arquivo do estado de SP, 1990.

Toponímia e antroponímia no Brasil: Coletânea de estudos. 2. ed. São Paulo: FFLCH/USP, 1992.

Métodos e questões terminológicas na onomástica. Estudo de caso: o Atlas Toponímico do Estado de São Paulo. Investigações, v.9, Recife, UFPE, 1999.

Rede de conhecimento e campo lexical: hidrônimos e hidrotopônimos na onomástica brasileira. In ISQUERDO, A. N.; KRIEGER, M. G.. As Ciências do léxico. v. II. Campo Grande: Ed. UFMS, 2004. p.121-130. 
FAZENDA, I. C. Interdisciplinaridade: história, teoria e pesquisa. 8. ed. Campinas: Papirus, 2001.

.(Org.) O que é interdisciplinaridade? São Paulo: Cortez, 2008.

.Interdisciplinaridade: definição, projeto, pesquisa. In: FAZENDA, In. C. A. $\overline{(\text { Org.) }}$; FELDMAN, M. (Org.); PASSOS, L. F. (Org.). Práticas Interdisciplinares na Escola. 11. ed. São Paulo: Cortez, 2009. 147 p

FERREIRA, Sandra Lúcia. Introduzindo a noção de interdisciplinaridade, In: FAZENDA, I. C. A. (Org.); FELDMAN, M. (Org.); PASSOS, L. F. (Org.). Práticas Interdisciplinares na Escola. 11. ed. São Paulo: Cortez, 2009. 147 p

FIGUEIREDO, A. D. Redes e educação: a surpreendente riqueza de um conceito. Disponível no sítio http://www.teresianasstj.net/files/met/RedeseEducao.pdf. Acesso em: 3 de março de 2011.

FREIRE, P. Pedagogia da autonomia: saberes necessários à prática educativa. Rio de Janeiro: Paz e Terra, 1996.

JAPIASSU, H.. Interdisciplinaridade e patologia do saber. Rio de Janeiro: Imago, 1976. $220 \mathrm{p}$.

LAKOFF, G.; JOHNSON, M. Metaphors We Live By. Chicago: The University of Chicago Press, 1980.

.The Contemporary Theory of Metaphor. Manuscript. University of California at Berkeley, 1992.

LEFEBVRE, H.. La Presencia y la ausencia contribución a la teoria de las representaciones. México: Fondo de Cultura Económica, 1983.

HOUAISS, A; VILLAR, Mauro de Salles. Dicionário Houaiss da Língua Portuguesa. Rio de Janeiro: Objetiva, 2001.

MACHADO, N. Epistemologia e Didática: as concepções de conhecimento e inteligência e a prática docente. São Paulo: Cortez, 1996.

MORIN, E. Introdução ao pensamento complexo. 3 ed. Lisboa: Instituto Piaget, 1990. $177 \mathrm{p}$. 
SANTOS, B. S. Um discurso sobre as ciências na transição para uma ciência pósmoderna. Estudos avançados. São Paulo, v. 2, n. 2, maio/agosto, 1988.. Disponível em: $<$ http://www.scielo.br/scielo.php?script=sci_arttext\&pid=S0103-40141988000200007. Acesso em: 8 de março de 2011.

ULLMANN, S. Semântica: uma introdução ao significado. 4. Ed. Lisboa: Fundação Calouste Gulbenkian, 1964.

Artigo recebido em: 12.03 .2012

Artigo aprovado em: 01.06.2012 